\title{
An Approach to the Examination of the Fetal Congenitally Malformed Heart at Autopsy
}

\author{
Lance K. Erickson ${ }^{1,2}$
}

Received: 23 June 2015/ Accepted: 12 October 2015/Published online: 4 November 2015

(C) Society of Fetal Medicine 2015

\begin{abstract}
Examination of the congenitally malformed fetal heart at autopsy presents many unique challenges. A systematic approach is needed to identify accurately the underlying morphology of the fetal heart, with adjustment to the routine cardiac exam as necessary in the most extreme malformed cases. In situ examination can provide details of pre-mortem function, based on what is seen externally, and direct the internal examination. Ultimately, an accurate morphological description of the fetal heart at any gestational age is necessary for correct diagnosis. Information that confirms or adds to prenatal imaging or testing provides a bridge for communication in diverse clinical settings including the care of other patients with similar presentations. The heart findings should be integrated into interdisciplinary discussions of major findings and during counseling sessions with parents who seek explanations for fetal loss and risk of recurrence in future pregnancies.
\end{abstract}

Keywords Congenital heart disease - Fetal autopsy · Heart examination - Sequential segmental analysis - Fetal heart

Lance K. Erickson

lance.erickson@imail.org

1 Division of Pediatric Pathology, University of Utah, Salt Lake City, UT, USA

2 Primary Children's Hospital, 100 N. Mario Capecchi Drive, Salt Lake City, UT 84113, USA

\section{Introduction}

The autopsy benefits from the input of clinicians involved with the mother and fetus. Patient history and clinical information from medical geneticists, genetic counselors, perinatologists, radiologists, and others should be reviewed before beginning the examination. The heart at autopsy is the result of reciprocal interactions between morphogenesis and function. Although a complete understanding of the fetal heart anatomy considers these processes through the course of gestation, cardiac pathology at autopsy only directly correlates with terminal physiology. Prior anatomic and functional events must be inferred. Communication with the obstetrician and fetal cardiologist can provide valuable information regarding pre-autopsy cardiac function. In addition to the direct benefit to a patient's family, correlation of autopsy findings with predicted and documented findings during intrauterine life is an important component of medical education and quality improvement, and improves care for other patients in various clinical settings.

Although the heart completes its four-chambered structure by the 7th developmental week [1], the valves and chamber sizes will continue to grow proportional to function throughout fetal life. Chamber volume, vessel size, and shape are dynamic and dependent on pressure and flow volumes. Dynamic change in ventricular size is exemplified by the sonographic progression of hypoplastic left heart syndrome, which often evolves from normal four chamber views with normal ventricular size early in gestation. Subsequent ultrasounds show diminishing size of the left ventricle as flow volumes shift from entering the left ventricle to left-to-right flow across the atrial septum and through the right ventricle. Final examination of the heart at autopsy may reveal complete elimination of blood 
flow to the left ventricle and the chamber size reduced to a mere slit-like remnant.

Postmortem examination of the fetal heart presents a unique opportunity to observe the early features of cardiac development and the differences between fetal circulation and the immediate circulatory changes in the newborn. There are, however, many limitations with these types of investigations. Early gestational age fetuses may be limited by size alone. The defining characteristics of cardiac form and the most constant morphologic component of each segment are recognizable in even the smallest of fetuses. Stereomicroscopy and the use of microdissection instruments allow visualization of fetal hearts as early as 8-10 weeks gestation. Alternatively, very small hearts can be embedded in paraffin and analyzed by serial or step sectioning.

Intrauterine retention time after prenatal death is often a major contributing factor in the ability to perform a complete examination. Tissues that show extensive maceration require delicate handling. Manipulation of these tissues can result in complete breakdown and liquefaction. Although postmortem ultrasound or MRI have been employed to complement the autopsy for severely macerated fetuses [2, $3]$, in most cases, the prosector has the only chance to document lesions before the morphology is destroyed by manipulation. Special care should be taken at the time of in situ examination of the thoracic cavity in a macerated fetus, as many common forms of congenital heart disease can be diagnosed without intracardiac dissection and external findings may direct what limited internal evaluation is possible.

\section{Sequential Segmental Analysis}

A systematic approach with the correct instrumentation allows for identification of major and minor congenital lesions. The ideal approach to the congenitally malformed heart, regardless of gestational age, provides categorization and description of all lesions. It is not necessary to have spent many years in a cardiology clinic to be able to understand the terminology and structure of the cardiac components in congenitally malformed hearts. A system of nomenclature that has proven accuracy has been developed and refined by Anderson and Shirali [4], namely "sequential segmental analysis" (SSA) [5, 6]. The system describes and identifies the basic and advanced lesions of the heart in terms useable across disciplines. Using SSA, the heart is broken down into basic cardiac components as atrial, ventricular, and arterial segments along with their connections. Each segment is described based on its most constant morphologic component. For example, description of a heart with congenitally corrected transposition (CCT) using SSA might be described as follows:

The atria have the usual arrangement of a morphologic right atrium on the right and a morphologic left atrium on the left, based on the right atrium having pectinate muscles that extend along the entire circumference of the atrioventricular connection and the left with pectinate muscles confined to the appendage. Discordant atrioventricular connections are present as the right atrium connects with a morphologic left ventricle and vice versa on the left side. The right-sided, but morphologically left, ventricle has fine crisscrossing trabeculations and a smooth outlet septum while the left-sided ventricle has course trabeculations throughout the chamber. The ventriculoarterial connections are also discordant with the right-sided morphologic left ventricle connecting to the pulmonary artery and the left-sided morphologic right ventricle connecting to the aorta.

The arterial segments are described and defined based on their connections to the systemic and pulmonary circulations. The aorta and pulmonary artery are also described by the position of their valves relative to one another at the base of the heart. In our hypothetical CCT case, a single sentence description encompassing the SSA system could then be reported as: "The heart has the usual atrial arrangement with discordant atrioventricular and ventriculoarterial connections, a left-handed looping pattern, and normally related great vessels." This simple description of a complicated anatomy summarizes, in a succinct manner, the arrangement and morphology of the malformed heart.

SSA is currently employed for fetal echocardiographic exams [7]. However, such systematic review of the fetal heart is not utilized on a routine basis for normal ultrasound visits during pregnancy. Instead, only a fetal heart rate and four-chamber view are obtained to assess the cardiac form and function. Even with the best technique, experience, and attention to detail at fetal cardiac ultrasound, limitations persist to what can be identified, the detection rate, and the accuracy across centers at different gestational ages [8, 9]. The autopsy remains the definitive examination for the complete description of the extent and categorization of cardiac lesions [10, 11].

\section{In Situ External Examination}

Congenital heart disease manifests itself in ways that can be identified in situ before any incisions to the heart have been made (Table 1). Clues to the underlying morphology range from the most subtle to the diagnostically obvious 
Table 1 Incidence of congenital heart disease with gross in situ identifiable features

\begin{tabular}{|c|c|c|}
\hline Lesion & $\begin{array}{l}\text { Median } \\
\text { percentage }^{\mathrm{a}}\end{array}$ & Identifiable features at the in situ examination \\
\hline Ventricular septal defect & 32.4 & $\begin{array}{l}\text { Usually no definitive external features, size of ventricles and position of great arteries can be } \\
\text { helpful }\end{array}$ \\
\hline Atrial septal defect & 7.5 & No external features \\
\hline Pulmonic stenosis & 7.0 & Discordance in caliper of the great arteries with hypoplastic pulmonary artery \\
\hline Patent arterial duct & 6.8 & Normal finding in the fetus \\
\hline Tetralogy of Fallot & 5.2 & $\begin{array}{l}\text { Prominent right ventricle shape and discordance in caliper of great arteries with aortic } \\
\text { dominance }\end{array}$ \\
\hline Coarctation of the aorta & 4.8 & $\begin{array}{l}\text { Stenosis usually seen proximal to the arterial duct and can have a dominant patent ductal aortic } \\
\text { arch }\end{array}$ \\
\hline $\begin{array}{l}\text { Transposition of the great } \\
\text { arteries }\end{array}$ & 4.4 & Abnormal great artery position at the base of the heart \\
\hline Aortic stenosis & 3.9 & Discordance in caliper of the great arteries with hypoplastic ascending aorta \\
\hline Atrioventricular septal defect & 3.8 & No external features \\
\hline Hypoplastic left heart & 2.8 & $\begin{array}{l}\text { Interventricular coronary arteries define right and left ventricle size, coarctation, hypoplastic } \\
\text { ascending aorta, prominent arterial duct }\end{array}$ \\
\hline Hypoplastic right heart & 2.2 & $\begin{array}{l}\text { Anterior and posterior interventricular coronary arteries define right and left ventricle size, } \\
\text { hypoplastic main pulmonary artery }\end{array}$ \\
\hline Double outlet right ventricle & 1.8 & $\begin{array}{l}\text { Abnormal great artery position at the base of the heart, necessary to correlate position, } \\
\text { atrioventricular and ventriculoarterial connections with internal findings }\end{array}$ \\
\hline Double inlet left ventricle & 1.5 & $\begin{array}{l}\text { Abnormal great artery position at the base of the heart, necessary to correlate position, } \\
\text { atrioventricular and ventriculoarterial connections with internal findings }\end{array}$ \\
\hline Common arterial trunk & 1.4 & Shared common artery branches to pulmonary and systemic arteries \\
\hline $\begin{array}{l}\text { Total anomalous pulmonary } \\
\text { venous connection }\end{array}$ & 1.0 & Absent pulmonary venous connections \\
\hline Miscellaneous & 10.1 & \\
\hline
\end{tabular}

${ }^{a}$ Median percentages of congenital heart disease from source: Hoffman and Kaplan [16]

(Table 2). Size limitations can be overcome by utilizing a dissecting microscope and fine dissecting instruments. A camera mounted to the microscope can document findings at all steps in the process.

The first observation after removing the chest plate is to identify the position of the cardiac mass within the chest (Fig. 1). Next, note the position and direction of the cardiac apex. Take care in removing the thymus as the innominate vein is connected to the posterior thymus and is easily torn or cut. Assessment of the systemic venous return is difficult without the innominate vein intact. Using blunt techniques instead of sharp and cutting dissection to remove the thymus before opening the pericardium will result in maintaining the best intact morphology. Atrial arrangement can be assessed to a limited extent during the in situ external exam. The size and shape of each atrium should be assessed. A morphologic right atrial appendage will usually have a triangular shape with a broad connection to the caval veins or atrial chamber. A morphologic left atrial appendage will have a more tubular shape with a narrow connection to the rest of the left atrium. Often, a left appendage will have a small hook at the apex of the appendage. The most constant morphologic component of the atriums will be the extent of the pectinate muscles around the vestibule of the adjacent atrioventricular valve, which is assessed during the internal examination. The next component for documented observation externally is the ventricular mass. Both size and shape should be documented [12]. A marker for determining the size of the ventricles is the anterior and posterior interventricular coronary arteries. The anterior descending vessel, except in rare circumstances, will course between the interventricular space and define the right from left ventricles anteriorly. Posteriorly, the descending coronary vessel is more variable as to its course but most often runs in the interventricular space. Next, the great arteries at the base of the heart should be studied, including diameter, relative position to the other, location at the base, and branching patterns. Before following the arch of the aorta, assess the venous return to the heart. The superior and inferior caval veins should return to the right atrium. The supply to the superior caval vein should include the azygous, innominate, subclavian, and jugular veins at the level of the shoulder girdle. Care should be taken in 
Table 2 Examination of the fetal congenitally malformed heart with external diagnostic aids

\begin{tabular}{|c|c|}
\hline $\begin{array}{l}\text { Abnormal on } \\
\text { examination }\end{array}$ & Potential diagnostic considerations with lesions present \\
\hline Cardiac position in chest & $\begin{array}{l}\text { Diaphragmatic hernia, extracardiac thoracic mass, pulmonary hypoplasia, severe vertebral/skeletal anomalies, } \\
\text { abnormal looping }\end{array}$ \\
\hline Position of cardiac apex & $\begin{array}{l}\text { Situs inversus, congenitally corrected transposition, hypoplastic ventricles, midline sternal defects, abnormal looping, } \\
\text { heterotaxy }\end{array}$ \\
\hline Shape of the heart & $\begin{array}{l}\text { Tetralogy of Fallot, hypoplastic ventricles, atrioventricular and/or arterial valvar atresia/stenosis/dysplasia/number of } \\
\text { cusps, ventricular septal defects, cardiomyopathies }\end{array}$ \\
\hline Systemic venous return & $\begin{array}{l}\text { Absent innominate vein-persistent left superior caval vein, anomalous systemic venous connections, anomalous } \\
\text { pulmonary venous connections, separate hepatic and inferior caval vein insertions }\end{array}$ \\
\hline $\begin{array}{l}\text { Size and shape of } \\
\text { atriums }\end{array}$ & $\begin{array}{l}\text { Ebstein anomaly, atrioventricular and/or arterial valvar atresia/stenosis/dysplasia/number of cusps, cor triatriatum, } \\
\text { atrial septal defects, anomalous pulmonary venous connections, common atrium, heterotaxy }\end{array}$ \\
\hline $\begin{array}{l}\text { Size and shape of } \\
\text { ventricles }\end{array}$ & $\begin{array}{l}\text { Hypoplastic left heart, pulmonary atresia with intact septum, atrioventricular and/or arterial valvar atresia/stenosis/ } \\
\text { dysplasia/number of cusps, cardiomyopathy, congenitally corrected transposition, ventricular septal defects }\end{array}$ \\
\hline Great arteries position & $\begin{array}{l}\text { Transposition, congenitally corrected transposition, double outlet ventricles, common arterial trunk, tetralogy of } \\
\text { Fallot, aorticopulmonary window, ventricular septal defects }\end{array}$ \\
\hline Great arteries caliper & $\begin{array}{l}\text { Hypoplastic ventricles, arterial valve atresia/stenosis/dysplasia/number of cusps, tetralogy of Fallot, coarctation, } \\
\text { aorticopulmonary window, ventricular septal defects, interrupted aortic arch }\end{array}$ \\
\hline Great arteries branching & $\begin{array}{l}\text { Transposition, common arterial trunk, interrupted aortic arch, coarctation, aorticopulmonary window, right sided } \\
\text { aortic arch }\end{array}$ \\
\hline $\begin{array}{l}\text { Pulmonary venous } \\
\text { connection }\end{array}$ & Total or partial anomalous pulmonary venous connections \\
\hline Aortic arch & $\begin{array}{l}\text { Interrupted aortic arch, coarctation, right-sided arch, anomalous vessels, aortic ring, double aortic arch, right aortic } \\
\text { arch }\end{array}$ \\
\hline Arterial duct & Atresia, absent duct, ductal arch, interrupted aortic arch, coarctation \\
\hline
\end{tabular}

preserving these branches and tracing the continuous flow to the heart to assure oneself of the lack of anomalous venous return. Once assured of the venous connections, the innominate vein can be transected to allow a better view of the arch vessels. Lastly, the in situ examination should follow the arch of the aorta and document the branching pattern of the vessels. The patency of the arterial duct, its connections, diameter, and length should be assessed. The ductal connection with the aorta and view of the descending aorta to check for coarctation can be accomplished by traction on the left lung moving it medially and inferiorly to look directly at the arch and arterial duct connections (Fig. 1).

There are limitations to the in situ external examination. However, external examination and documentation provides a context for internal form, which often has predictable correlations with growth and final functional anatomy. Intrinsic morphology that defines the chambers is only seen during the internal examination, which includes assessment of the atrial and ventricular septums and chamber connections. Stenosis and atresia of valves are suggested in situ based on comparative sizes but the valvar apparatus should be studied during the internal examination.

\section{Opening the Heart and Internal Examination}

The internal examination of the heart can be challenged by the need for fine dissecting instruments, magnification, and manual dexterity. Slight manipulation from the smallest of dissecting instruments can lead to extensive disruption of internal morphology, particularly in cases of advanced maceration. Overnight formalin fixation may help in preserving some of the morphology and allowing for crosslinking of proteins that aid in hardening soft tissue components. When possible, the entire fetus may be placed in fixative for superior preservation. When entire body fixation is not possible, the entire chest, branching vessels, and neck contents should be removed and fixed together. Use of forceps in a grabbing and pulling motion is discouraged. This movement can easily tear the delicate tissues. Opening the incisions with a blunt pushing motion and irrigating the surfaces along the cut with a syringe full of fixative has proven to be a delicate alternative to grabbing and forceful opening with forceps. Even with extreme care, the initial cuts and exposure sometimes offers but a brief chance to identify intrinsic internal morphology in the advanced macerated fetus. 

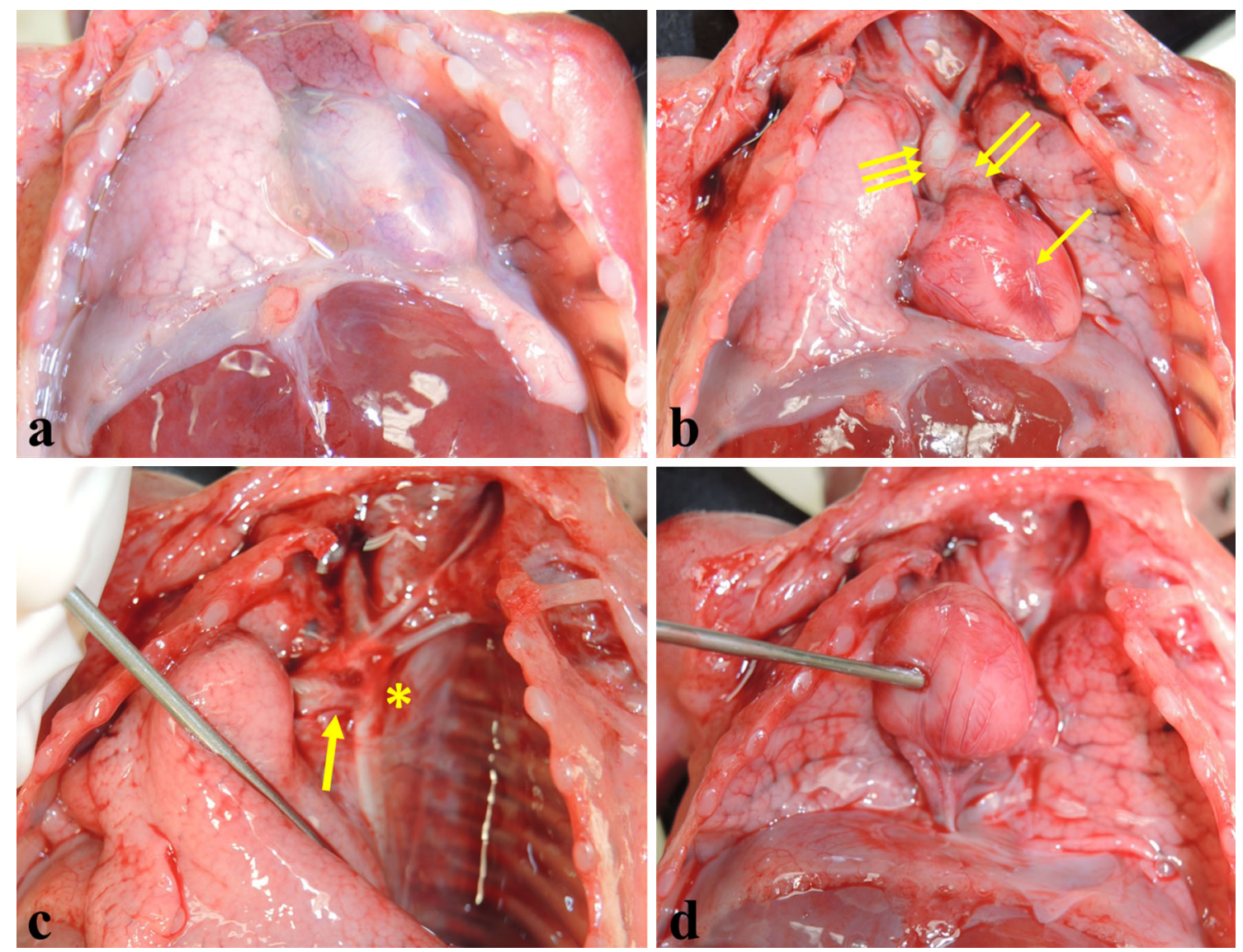

Fig. 1 Fetal heart in situ at 19 weeks gestation with views of the external examination. a Chest in situ with intact pericardium and thymus. b Single arrow anterior descending interventricular coronary artery, double arrow main pulmonary artery positioned anterior and to the left of the aorta, triple arrow aorta positioned posterior and to the

The dissection of the heart whether fresh or post-fixation should follow the flow of blood through the heart (Fig. 2). Slight modification will have to be made to this direction of flow in cases of valvar atresia, extensive valvar stenosis, extreme chamber hypoplasia, or advanced internal malformations. The first entry to the heart is by the caval veins. A lateral cut from the inferior to the superior caval vein is made. Staying lateral and pointing dissecting instruments away from the atrial septum will help in keeping the integrity of the septum intact. A second cut perpendicular to this cut is made out the atrium superior to the atrioventricular junction and out the atrial appendage. This opening gives an excellent view of the atrial septum. The oval foramen and its patency can be assessed from this view. Patency of the coronary sinus can be demonstrated with a probe in the sinus coursing posterior to the left atrium. The next cut is posterior from atrium into the ventricle staying just off the ventricular septum and extending the cut to the apex. The posterior interventricular right of the main pulmonary artery c Aortic arch in situ view with arrow pointing to arterial duct and asterisk at the usual location of a constricting coarctation with the left lung pulled medial and inferior d Heart lifted superior to visualize the inferior interventricular coronary artery at the tip of the probe

artery course is a marker of the septum and avoiding this will keep errant cuts away from the ventricular septum. The atrioventricular inflow connection can then be documented. The next cut is from the apex through the outflow. Probing the tracts before cutting is recommended to guide the dissecting cuts. The angle of scissors for this cut is important to cut away from the heart and out the arterial valve. An open ventricular connection at the membranous level is an easy entrance point for errant scissors with a cut that could destroy ventricular morphology. Continue a cut from apex out the great artery across the arterial valve. Branching of the great artery and its infundibular attachment along with ventricular morphology and looping pattern will be demonstrated. The arterial duct can be probed along with the branch vessels at this point. The next entrance to the heart is from the lungs through the venous return to the atrium. Starting posteriorly, the pulmonary veins from each lung should enter the atrium. A probe to access each vein should be utilized to assure proper venous 

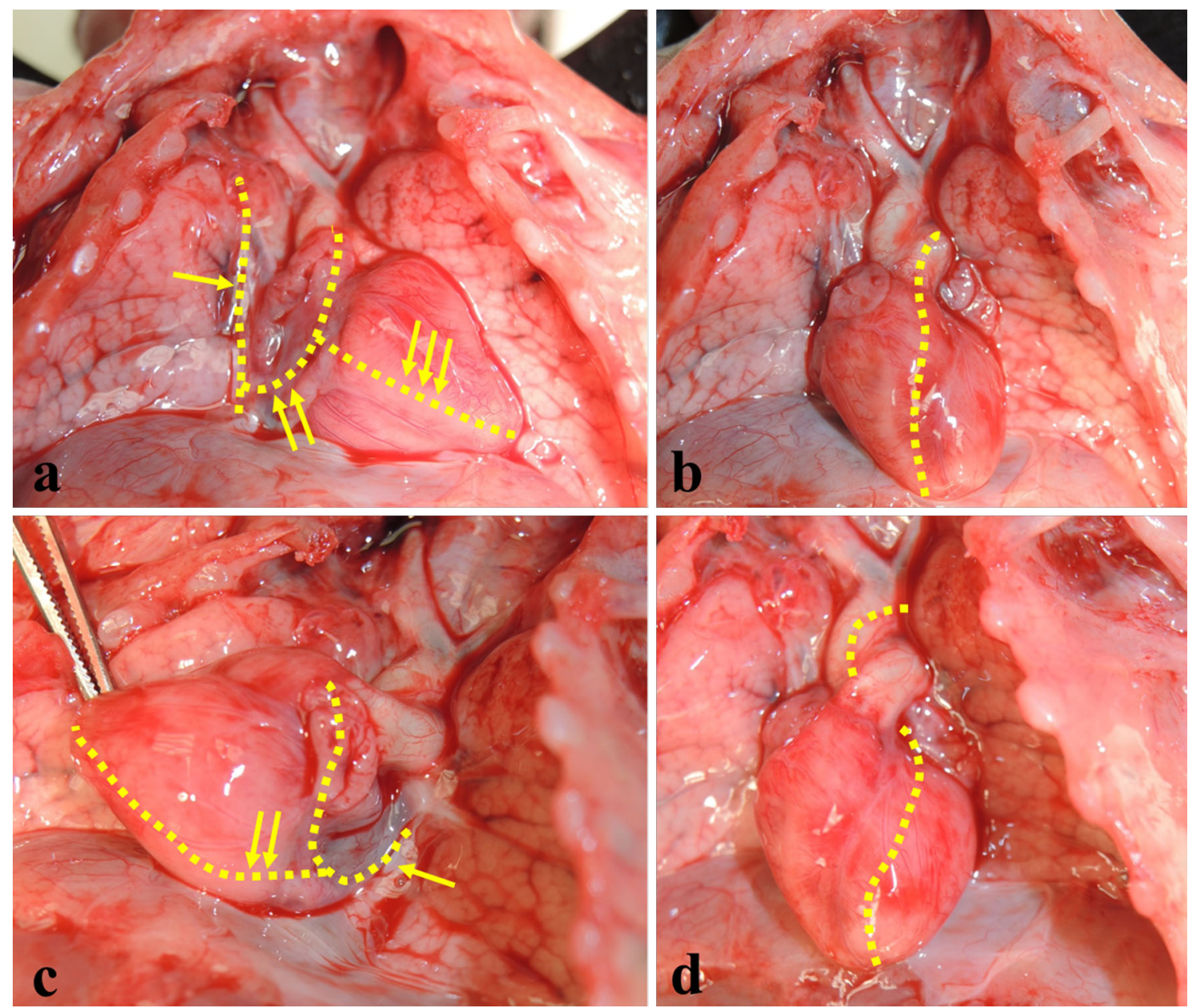

Fig. 2 Fetal heart at 19 weeks gestation with diagram of incisions for opening of the heart for internal examination. a Single arrow first incision from inferior caval vein to superior caval vein; double arrow incision perpendicular to the first cut and continuing to the apex of the atrial appendage; triple arrow right ventricular inflow cut posterior and just lateral of the interventricular coronary artery to the

connection. Next, cut from the posterior atrium around and out the atrial appendage. The atrial morphology can then be compared to the opposite side for correct assessment of atrial arrangement. The ventricular inflow cut is again made posteriorly avoiding the interventricular artery to the apex. The inflow atrioventricular connection can then be assessed and compared to the opposite ventricle. The outflow cut is made by changing to the anterior view of the heart and starting from apex extending the cut through the arterial valve while avoiding the atrial appendage. Because of the posterior and rightward position of the aortic valve in most hearts, often a spiraling cut around the base to the posterior portion of the great artery is necessary to avoid cutting the adjacent main artery. The valve, ventricular morphology, and infundibulum can then be documented and compared to the opposite side. ventricular apex. b Anterior right ventricle outflow cut. c Single arrow left side atrium cut starting at pulmonary veins and out the atrial appendage; double arrow posterior left ventricle inflow cut just lateral to interventricular coronary artery d Anterior view left sided ventricle outflow cut spiraling around the anterior artery to the posterior aorta and around the arch

\section{Conclusion}

Using a systematic approach to the fetal heart at autopsy allows for identification and categorization of all congenital lesions. The final description of morphology should be shared and discussed among the prenatal care team. A multidisciplinary approach to sharing final form and identified lesions typically includes specialists in medical genetics, obstetrics, delivery staff, genetic counselors, pathology, fetal cardiology, cardiovascular surgery, pediatric surgery, neonatology, and the primary care provider of the mother. The information from the autopsy contributes to a continuum of care for the mother and family [13]. The information is also directly applicable to the current and future living fetuses that may present with similar findings. 
Difficulty lies in interpretation of the different congenital heart nosologies. A continuing and real problem often expressed is, what to call a lesion. The debate has been contentious and continues to be debated. A present push for a common nomenclature and cross referencing of terms is underway on a global scale [14]. Reproducible, common, and meaningful terms within a complete description should leave no doubt as to the lesions present regardless of the nomenclature utilized. Every effort to convey the context to every potential reader should be the basis of a good and complete cardiac evaluation and reported findings. This can be accomplished by a description in true anatomic terms with attitudinally correct descriptors [15]. I have recommended nosology used in SSA because it is straightforward, uncomplicated, and easily understood by practitioners from diverse disciplines.

\section{Compliance with Ethical Standards}

Conflict of interest None.

\section{References}

1. Sadler TW. Cardiovascular System. In: Coryell P, editor. Langman's medical embryology. 7th ed, chap 12. Baltimore, Maryland: Lippincott Williams \& Wilkins; 1995. 460 pp.

2. Cain MA, Guidi CB, Steffensen T, Whiteman VE, Gilbert-Barness E, Johnson DR. Postmortem ultrasonography of the macerated fetus complements autopsy following in utero fetal demise. Pediatr Dev Pathol. 2014;17(3):217-20.

3. Arthurs OJ, Thayyil S, Olsen OE, Addison S, Wade A, Jones R, et al. Diagnostic accuracy of post-mortem MRI for thoracic abnormalities in fetuses and children. Eur Radiol. 2014;24(11): 2876-84.
4. Anderson RH, Shirali G. Sequential segmental analysis. Ann Pediatr Cardiol. 2009;2(1):24-35.

5. Craatz S, Künzel E, Spanel-Borowski K. Classification of a collection of malformed human hearts: practical experience in the use of sequential segmental analysis. Pediatr Cardiol. 2002;23(5): 483-90.

6. Devine WA, Debich DE, Anderson RH. Dissection of congenitally malformed hearts, with comments on the value of sequential segmental analysis. Pediatr Pathol. 1991;11(2):235-59.

7. Yoo SJ, Lee YH, Cho KS, Kim DY. Sequential segmental approach to fetal congenital heart disease. Cardiol Young. 1999;9(4):430-44.

8. Clur SA, Bilardo CM. Early detection of fetal cardiac abnormalities: how effective is it and how should we manage these patients? Prenat Diagn. 2014;34(13):1235-45.

9. Khalil A, Nicolaides KH. Fetal heart defects: potential and pitfalls of first-trimester detection. Semin Fetal Neonatal Med. 2013;18(5):251-60.

10. Ernst LM. A pathologists perspective on the perinatal autopsy. Semin Perinatol. 2015;39(1):55-63.

11. Taylor GP, Faye-Petersen OM, Ernst L, LeGallo RD, Schauer GM, Williamson AK, et al. Small patients, complex challenging cases: a reappraisal of the professional efforts in perinatal autopsies. Arch Pathol Lab Med. 2014;138(7):865-8.

12. Archie JG, Collins JS, Lebel RR. Quantitative standards for fetal and neonatal autopsy. Am J Clin Pathol. 2006;126(2):256-65.

13. Breeze AC, Statham H, Hackett GA, Jessop FA, Lees CC. Perinatal postmortems: what is important to parents and how do they decide? Birth. 2012;39(1):57-64.

14. Giroud JM, Jacobs JP, Spicer D, Backer C, Martin GR, Franklin $\mathrm{RC}$, et al. Report from the international society for nomenclature of paediatric and congenital heart disease: creation of a visual encyclopedia illustrating the terms and definitions of the international pediatric and congenital cardiac code. World J Pediatr Congenit Heart Surg. 2010;1(3):300-13.

15. Anderson RH, Spicer DE, Hlavacek AJ, Hill A, Loukas M, et al. Describing the cardiac components-attitudinally appropriate nomenclature. J Cardiovasc Transl Res. 2013;6(2):118-23.

16. Hoffman JI, Kaplan S. The incidence of congenital heart disease. J Am Coll Cardiol. 2002;39(12):1890-900. 